\title{
Extraction of natural dye from Osyris quadripartita and application in dyeing of cotton fabrics
}

\begin{abstract}
The uses of non-allergic and non-toxic natural dyes on textile materials have become a matter of significant importance. In spite of much research work being done on natural dye application on textile materials, its performance is not yet satisfactory. This is because their better performance has not been broadly or systematically studied. In this investigation, an attempt has been made to study the dye-ability of cotton fabric using natural dye extracted from Osyris quadripartita (Qerete) plant. The extraction parameters have been studied to obtain optimum dye extract. Dyeing with and without mordant was conducted. Pre-, Meta- and Post- mordanting techniques were applied. The dyed samples were analyzed in terms of fastness properties. The percentage of loss in moisture content from the plant leaves was $4.7 \%$ and the moisture regain was $4.9 \%$. The light fastness obtained from the dyed fabric was $4 / 5$. Similarly, the dry crock fastness for directly dyed cotton sample was $5 / 5$, while the wet crock fastness of direct dyed cotton test result recorded grade was $4 / 5$. Furthermore, the washing fastness obtained was $5 / 5$. The results of this investigation led to the conclusion that direct dyeing without mordant is feasible with the better fastness properties of cotton dyeing with natural dyes.
\end{abstract}

Keywords: natural dyes, cotton fabrics, mordants, fastness properties
Volume 3 Issue 4 - 2017

\author{
Negasi Teklay, Rotich K Gideon \\ Ethiopian institute of textile and fashion technology, Bahir Dar \\ University, Ethiopia
}

\begin{abstract}
Correspondence: Dr. Rotich K Gideon, Ethiopian institute of textile and fashion technology, Bahir Dar University, P.O Box 1037, Bahir Dar,Amhara, Ethiopia, Tel 251929464630, Email rotichgideon@yahoo.com
\end{abstract}

Received: December 02, 2017 | Published: December 13,

2017

\section{Introduction}

Natural dyes are widely used in the coloring of food, leather and wood. ${ }^{1}$ Traditionally they were the only colorants for textile fibers like wool, silk, cotton and flax. Their use in textiles declined drastically with the introduction of synthetic dyes in $1856 .{ }^{2-6}$ Presently the use of synthetic dyes is estimated at around 10,000,000tons per annum. ${ }^{7-11}$ The manufacture and use of this large quantity of dyes give rise to sizeable amounts of waste and unfixed colorants creating serious health hazards and distressing the eco-balance of nature. ${ }^{12}$ Currently, the heighten consciousness about environmental has had the effect in the imposition of strict eco-standards in several parts of the world in reaction to harmful reactions connected with synthetic dyes. ${ }^{13}$ For this reason, there has been a growing demand for natural dyes in the past few decades. ${ }^{14}$ The sources of natural dyes are diverse which include timber and food industry wastes. ${ }^{15}$ A number of studies have been done comparing the use and performance of natural against synthetic dyes on wool and silk ${ }^{12,16}$ and cotton..$^{17,18}$ Nevertheless, natural dyes are not readily obtainable due to few organized manufacturers and non-standardization of raw material and production process. The process of application is intricate thus further hindering the use of natural dyes.

Ethiopia has a rich tradition of using natural sources for textile coloration. ${ }^{7,19,21}$ This is verified by the vibrant colors present in the ancient hand-written bibles and traditional garments worn by the monks in the monasteries. There are also publications regarding the use of certain indigenous plants as dye sources. ${ }^{22}$ However Ethiopia has a broad range of flora that offer uncharted dye sources. Qerte (Osyris quadripartita) is found in Tigray, Oromia and Addis Ababa areas of Ethiopia. The plant is locally used for dyeing of baby holding garment (locally called Ankelba).The objective of this research is to investigate the extraction and application of dye from leaves of Qerte on cotton fabric. The parameters of dye extraction and application have been optimized. Characterization of the extracted dye has also been carried out using aqueous extraction method. Lastly, the desirable properties of the dyed fabric were evaluated in accordance with international standards.

\section{Materials and methods}

\section{Materials}

The leaves of the Osyris quadripartite plant, as shown in Figure 1, were collected from Bahir Dar country side. Conventionally desized, scoured and bleached plain weave cotton fabric (220ends/dm, 180 picks $/ \mathrm{dm}, 120 \mathrm{~g} / \mathrm{m}^{2}$ ), obtained from Bahir Dar Textile Share Company, Ethiopia, was used for the study. Analytical reagent (AR) grade ferrous sulphate, aluminum sulphate, potassium dichromate, stannous chloride, sodium chloride and standard soap were used. Depending upon the metallic salt (mordant) used, the colour obtained on dyed fabric from the leaves of Osyris quadripartite extract differed.

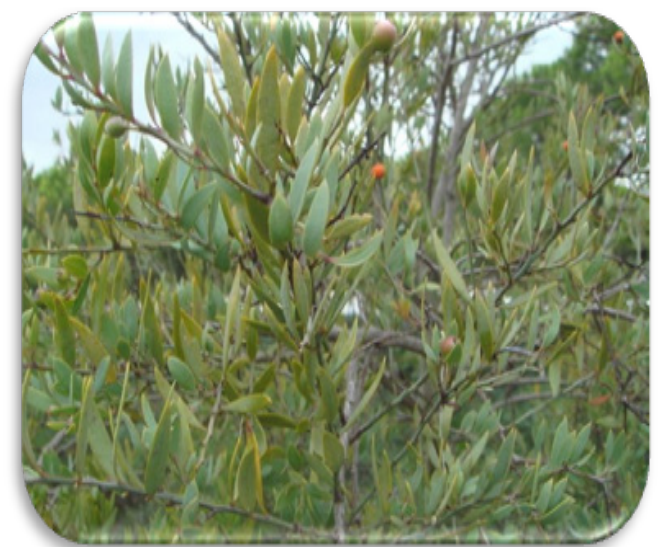

Figure I Osyris quadripartite plant. 


\section{Methods}

Dye extraction and optimization: Aqueous extraction method was employed for extracting coloring components from Qerte leaves. The raw material (leaves) was collected and dried then ground into fine powder with the use of mortar and pestle. The powder was soaked in distilled water at MLR of $(1: 100,1: 125,1: 150,1: 175,1: 200,1: 225$ and $1: 250)$ heated to a temperature of $\left(60^{\circ} \mathrm{C}, 80^{\circ} \mathrm{C}, 100^{\circ} \mathrm{C}\right.$ and $\left.120^{\circ} \mathrm{C}\right)$ and the extraction time of $30 \mathrm{~min}, 45 \mathrm{~min}$ and $60 \mathrm{~min}$ was used. The solution was cooled, filtered and evaluated for its absorbance using a UV visible spectrophotometer (Model lambda25). The temperature, concentration and time combination that yielding maximum absorption were taken as the optimum condition of extraction of dye.

Determination of percentage of dye yield: The dye percent of yield was calculated using equation (1)

Percent of dye yield $=\frac{\text { mass of plant leaves }- \text { mass of dried precipitate }}{\text { mass of plant leaves }} * 100$

Dyeing of cotton fabrics: The cotton fabric samples were entered into ECO IR dyeing machine with optimum extracted dye. The dyeing was carried out for 45 minutes at $80^{\circ} \mathrm{C}$ with MLR of 1:10, 1:20, 1:30 and 1:40. The dyed samples were washed and dried, after the color strength was observed using color eye 3100 . Higher $\mathrm{K} / \mathrm{S}$ value means good absorption of the dye and this value was selected as an optimized condition.

Evaluation of dyed cotton sample: Wash fastness of the samples dyed under the optimized conditions was tested according to ISO 105-CO3 method, rubbing fastness was tested by using ISO 105-X 12 methods and Color fastness of textile material to day light was tested according to ISO 105B02 method

\section{Result and discussion}

\section{Extraction of dye from Osyris quadripartite plant}

The absorption result of natural dye extracted from leaves of Osyris Quadripartita using aqueous extraction method are shown in Tables $1 \&$ Figure 2. The optimized condition was determined using UV-Visible spectroscopy (Lambda 25). From the results, the optimum conditions were 1:125 MLR extracted at a temperature of $80^{\circ} \mathrm{C}$ for 45 minutes (Table 2 \& Figure 2).

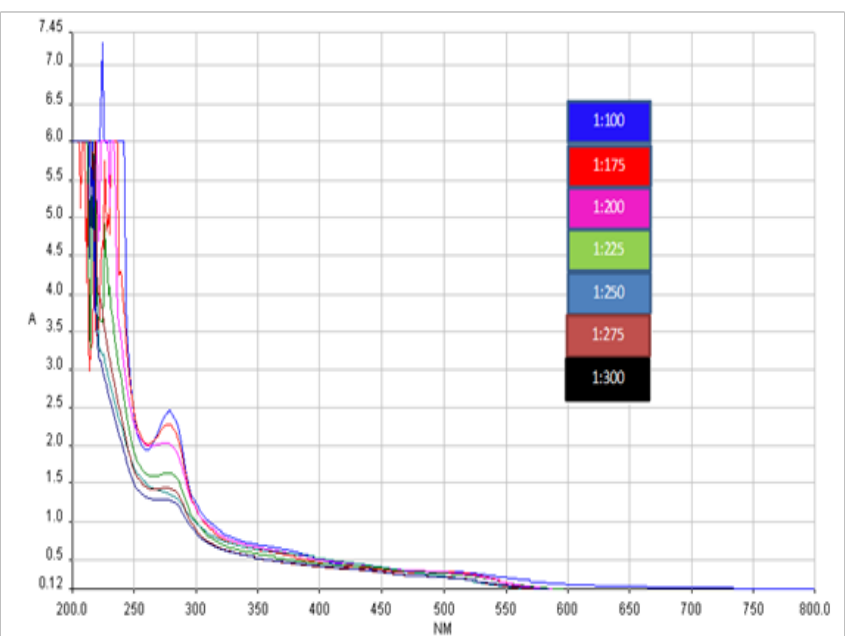

Figure 2 UV-visible spectrophotometer absorption data from 200-800 NM wave length.
From Figure 3, the MLR of 1:125 was selected because it had a high absorption as compared the others within the wavelength range of $480-520 \mathrm{~nm}$. This MLR was used in optimization of time and temperature. Figure 4 show the UV spectrophotometer of the extracted dye with the dilution of 1:21 at different temperatures. From Figure 4 , the temperature of $80^{\circ} \mathrm{C}$ was optimum since its absorption was greater than $60^{\circ} \mathrm{C}$ and $100^{\circ} \mathrm{C}$ but lower than at $120^{\circ} \mathrm{C}$, which is high and may cause degradation of the dye. Table 3 shows the optimization of extraction time while keeping other parameters constant.

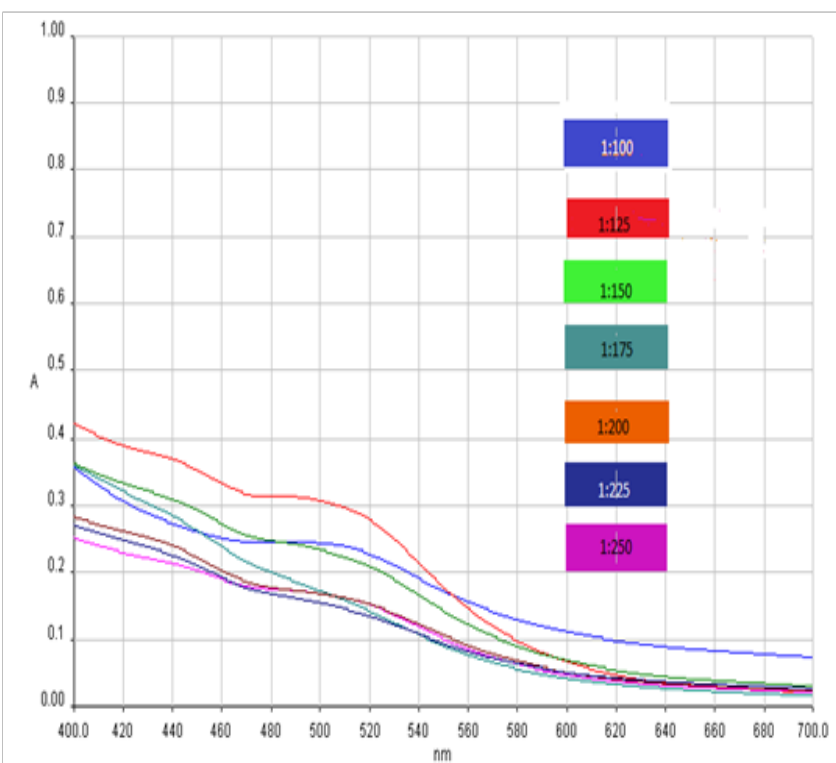

Figure 3 UV-visible spectrophotometer absorption data from 400-700 NM wave length.

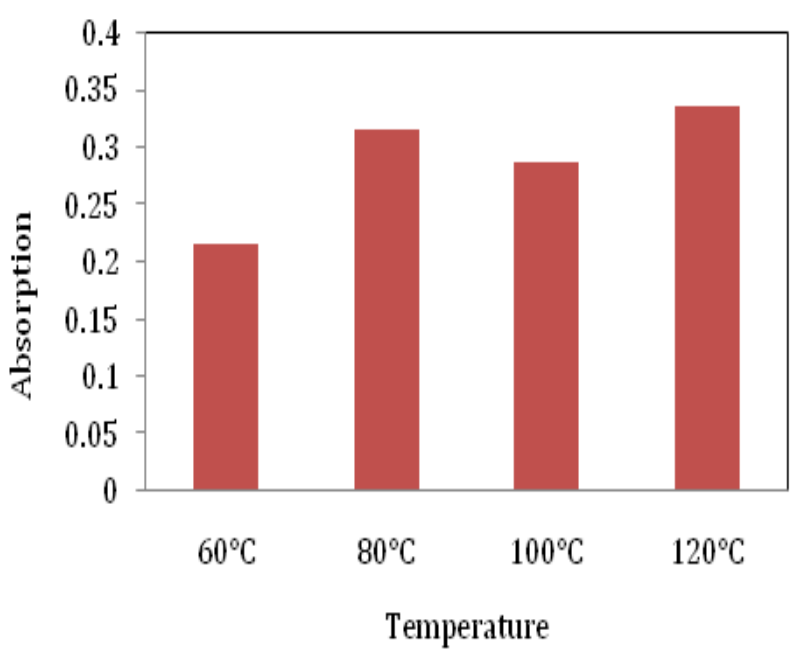

Figure 4 Optimization of temperature.

Table 3 shows different extractions carried out using 1:125 MLR, temperature of $80^{\circ} \mathrm{C}$ and different extraction time. Sample 3 had the highest absorption value of 0.35125 , compared to other samples 1 and 2. For this reason, the dye extracted from 1:125 MLR dye material concentration, at temperature of $80^{\circ} \mathrm{C}$ for 60 minutes was considered optimum condition, since high absorbance value was obtained with these conditions. The dye extract from these conditions was used for dyeing cotton fabric samples. 
Table I Varying the mass of plant leaves to get optimized MLR

\begin{tabular}{|c|c|c|c|c|c|}
\hline \multicolumn{6}{|c|}{$\begin{array}{l}\text { Extraction parameters } \\
\text { Time } 30 \mathrm{~min}, \text { Temperature } 80^{\circ} \mathrm{C}, \lambda \max 279 \mathrm{~nm}\end{array}$} \\
\hline Samples & $\begin{array}{l}\text { Material liquor ratio of } \\
\text { leaves to water }\end{array}$ & $\begin{array}{l}\text { Mass of plant leaves } \\
\text { in gm. }\end{array}$ & $\begin{array}{l}\text { Mass of dried } \\
\text { precipitate }\end{array}$ & $\begin{array}{l}\% \text { of dye } \\
\text { yield }\end{array}$ & $\begin{array}{l}\text { Absorption (A) } \\
\text { (dilute by } 1: 21 \text { ) }\end{array}$ \\
\hline I & I:I00 (I0g/l) & 1.5 & 0.6 & 60 & 2.4538 \\
\hline 2 & $\mathrm{I}: 125(8 \mathrm{~g} / \mathrm{l})$ & 1.2 & 0.54 & 55 & 2.28472 \\
\hline 3 & I:I50 (6.67g/l) & I & 0.42 & 58 & 2.28472 \\
\hline 4 & I:I75 (5.7|4g/l) & 0.8757 & 0.39 & 55.46 & 2.27648 \\
\hline 5 & $\mathrm{I}: 200(5 \mathrm{~g} / \mathrm{l})$ & 0.75 & 0.36 & 52 & 1.64298 \\
\hline 6 & I:225 (4.44g/l) & 0.67 & 0.32 & 52.23 & 2.04534 \\
\hline 7 & $\mathrm{I}: 250(4 \mathrm{~g} / \mathrm{l})$ & 0.6 & 0.29 & 51.67 & 1.64252 \\
\hline 8 & I:275 (3.63g/l) & 0.55 & 0.285 & 48.15 & 1.44266 \\
\hline 9 & $\mathrm{I}: 300(3.33 \mathrm{~g} / \mathrm{l})$ & 0.5 & 0.28 & 44 & 1.27614 \\
\hline
\end{tabular}

Table 2 Selection of MLR at $\lambda \max 486 \mathrm{~nm}$

\section{Extraction parameters}

Time $30 \mathrm{~min}$, Temperature $80^{\circ} \mathrm{C}, \lambda \max 486 \mathrm{~nm}$

\begin{tabular}{|c|c|c|c|c|c|c|c|}
\hline Material liquor ratio of leaves to water & 0.11111111 & 0.1284722 & 0.1458333 & 0.1631944 & 0.1805556 & 0.1979167 & 0.2152778 \\
\hline Absorption (A) (dilute by $I: 2 I$ ) & 0.24469 & 0.31408 & 0.24333 & 0.17384 & 0.19081 & 0.17448 & 0.16346 \\
\hline
\end{tabular}

Table 3 Optimization of time

\section{Constant parameters}

MLR I: I 25, $\chi \max 486 \mathrm{~nm}$, Extraction temperature $80^{\circ} \mathrm{C}$

\begin{tabular}{llll}
\hline Sample no. & Extraction time & \% of dye yield & Absorption (A) \\
I & $30 \mathrm{~min}$. & 58 & 0.31408 \\
2 & $45 \mathrm{~min}$ & 65 & 0.34331 \\
3 & $60 \mathrm{~min}$. & 69 & 0.35125
\end{tabular}

\section{Dyeing process}

The dyeing process was carried out using ECO IR dyeing machine with the optimized recipe obtained from section 3.1. Different concentrations of dyes were tested by varying the MLR on dyeing of the half bleached cotton fabric sample and their K/S value obtained (Figure 5).

As observed from Figure 5, 1:30 MLR ratio had the highest K/S value (1.3594) as compared with other MLR values. As the K/S value increased the color depth of dyed fabric also increased. For this reason, the optimum dyeing condition of 1:30 MLR, 45minutes at a temperature of $80^{\circ} \mathrm{C}$ was selected.

\section{Effects of salts}

To check the effect of addition of salts on the use of the extracted dye, three samples were dyed. The first sample had no salt, second had $5 \mathrm{~g} / \mathrm{l}$ of salt added and third had $10 \mathrm{~g} / \mathrm{l}$ of salt added. The dyed fabric $\mathrm{K} / \mathrm{S}$ value was evaluated and the results are shown in Figure 6.

From Figure 6, it can be seen that the K/S value (1.359) of dyed sample without addition of salt was the highest as compared to dyeing with addition of salt. Therefore this kind of natural dye is suitable for dyeing without addition of salt because it has good exhaustion in cotton fabric.

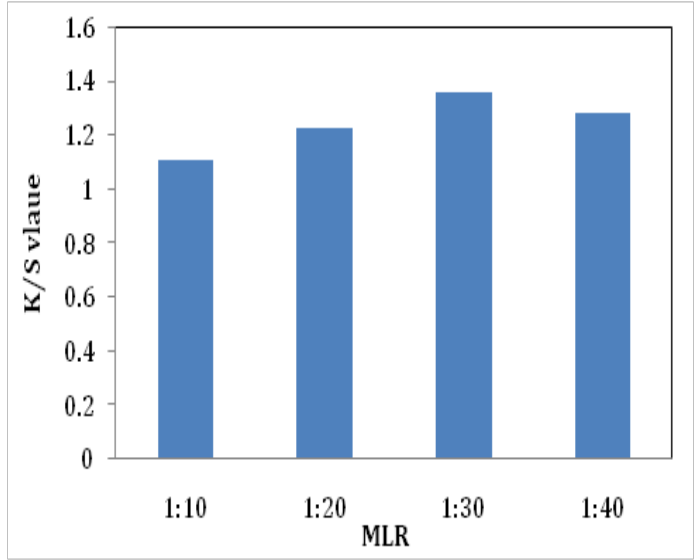

Figure 5 Optimization of MLR of the dye.

\section{Pre-mordanting methods}

Table 4 shows the effect of pre-mordanting of the natural dye on the cotton fabric. It can be seen that copper sulphate had the highest $\mathrm{K} / \mathrm{S}$ value. This shows that with the application of copper sulphate as a pre-mordant, a deep color can be obtained with the extracted natural dye.

\section{Simultaneous mordanting methods}

Similarly, it can be clearly seen from Table 5 that copper sulphate will give higher $\mathrm{K} / \mathrm{S}$ if used a simultaneous mordant when dyeing with the extracted natural dye. 


\section{Post mordant methods of dyeing}

For the use of post mordants, it can be seen from Table 6 that its application reduced the $\mathrm{K} / \mathrm{S}$ value when compared with no addition of post mordants.

The use of mordant changes the color of the dyed fabric as shown in Table 7 and increases the costs of the dyeing process, as well as the mordants are not environmental friendly. But without addition of mordants, it is possible to obtain good shade of the dyed fabric with good water and rubbing fastness. For this reason, this dye is economical and environmentally suitable for carrying out dyeing without addition of any auxiliary or mordants.

Table 4 Testing of the effect of pre-mordanting method

\begin{tabular}{|c|c|c|c|c|c|}
\hline \multicolumn{6}{|c|}{ Parameters used : MLR of dye I:30, Time $45 \mathrm{~min}$, Temperature $80^{\circ} \mathrm{C}$, Wave length $420 \mathrm{~nm}$} \\
\hline Mordant used & Aluminum sulphate & Potassium dichromate & Stannous chloride & Copper sulphate & No mordant \\
\hline $\mathrm{K} / \mathrm{S}$ & 1.3128 & 1.4235 & 1.7002 & 4.0059 & 1.3594 \\
\hline Color of dye solution & Light Red & Yellow & Dark Red & Yellow & Red \\
\hline
\end{tabular}

Table 5 Testing the effect of Meta- mordanting method

\begin{tabular}{|c|c|c|c|c|c|}
\hline \multicolumn{6}{|c|}{ Parameters used: MLR of dye I:30,Time $45 \mathrm{~min}$, Temperature $80^{\circ} \mathrm{C}$, Wave length $420 \mathrm{~nm}$} \\
\hline Mordants used & & & & & \\
\hline Mordant used & Aluminum sulphate & Potassium dichromate & Stannous chloride & Copper sulphate & No mordant \\
\hline $\mathrm{K} / \mathrm{S}$ & 1.567 & 1.1612 & 1.2516 & 5.9986 & 1.3594 \\
\hline Color of dye solution & Red & Yellow & Red & Yellow & Red \\
\hline
\end{tabular}

Table 6 Testing the effect of post mordanting method

Parameters used: MLR of dye I:30, Time $45 \mathrm{~min}$, Temperature $80^{\circ} \mathrm{C}$, Wave length $420 \mathrm{~nm}$

\section{Mordants used}

Mordant used

$\mathrm{K} / \mathrm{S}$

Color of dye solution

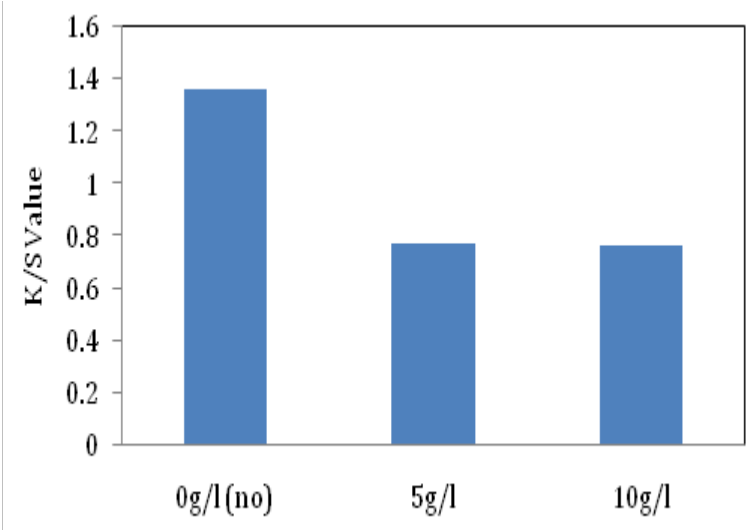

Salt Concentration

Figure 6 Effect of salt on dyeing.

\section{Testing of durability}

From Table 8, the grey scale showed that this dye had good dry and wet rubbing fastness. Because to obtain above grade $4 / 5$ indicates that during wearing, the fabric will resist any kind of rubbing from fading out of the dyed part of the fabric. Table 8 also shows that this dye does not fade during washing because after washing ten times, grade $5 / 5$ was still obtained which indicates excellent washing fastness. The light fastness was checked by solar box and the result obtained was

$\begin{array}{ll}\text { Copper sulphate } & \text { No } \\ 1.1169 & 1.3594 \\ \text { Red } & \text { Red }\end{array}$

grade $4 / 5$. This means the dyed cotton fabric had average resistant to light.

Table 7 Different shades caused by using mordants

\begin{tabular}{l}
\hline Sordants \\
\hline Potassium dichromate \\
\hline Aluminum sulphate \\
Stannous chloride \\
Direct dyeing without mordanting \\
Copper sulphate
\end{tabular}


Table 8 Testing of durability

\begin{tabular}{llllll}
\hline Parameters used & Results & & & \\
No. of wash cycles & I & $\mathbf{5}$ & $\mathbf{1 0}$ & $\begin{array}{l}\text { Not } \\
\text { wash }\end{array}$ \\
\hline $\begin{array}{l}\text { Washing } \\
\text { fastness }\end{array}$ & K/S & I.5438 & I.3995 & 1.3994 & I.3594 \\
& $\begin{array}{l}\text { Grey scale } \\
\text { Dry grey } \\
\text { scale }\end{array}$ & 5 & 5 & 5 & 5 \\
$\begin{array}{l}\text { Rubbing } \\
\text { fastness }\end{array}$ & 5 & 5 & 5 & 5 \\
\hline & $\begin{array}{l}\text { Wet grey } \\
\text { scale }\end{array}$ & 5-Apr & 5-Apr & 5-Apr & 5-Apr \\
\hline
\end{tabular}

\section{Conclusion}

This paper deals with extraction of natural dye from Osyris quadripartita plant and its application in dyeing cotton fabric. This plant is widely available in east Africa and has a potential to be a source of natural dye, for dyeing textile materials. The dye from Osyris quadripartita plant can be well extracted with dye material concentration of $1: 125 \mathrm{MLR}$ (8gpl) by boiling the material at $80^{\circ} \mathrm{C}$ for 60 minutes using aqueous extraction methods. Dyeing with extract was optimized with 1:30 MLR and dyeing for 45 minutes at $80^{\circ} \mathrm{C}$. Better color strength was achieved with copper sulphate with metamordant dyeing but copper sulphate is not environmental friendly. Direct dyeing of cotton without any addition of a mordant obtained better fastness properties for this kind of natural dye.

\section{Acknowledgements}

We would like to acknowledge the support of Ethiopian Institute of Textile and fashion Technology (EiTEX), Bahir Dar University, for their financial support and use of the labs.

\section{Conflict of interest}

Author declares there is no conflict of interest in publishing the article.

\section{References}

1. Kumar J, Sinha AK. Resurgence of natural colourants: a holistic view Natural product research. 2004;18(1):59-84

2. Pickering A. Decentering sociology: Synthetic dyes and social theory. Perspectives on Science. 2005;13(3):352-405.

3. Murmann JP, Homburg E. Comparing evolutionary dynamics across different national settings: the case of the synthetic dye industry, $1857-$ 1914. J Evolutionary Economics. 2001;11(2):177-205

4. Cristea D, Vilarem G. Improving light fastness of natural dyes on cotton yarn. Dyes \& Pigments. 2006;70(3):238-245.

5. Zollinger H. Color chemistry: syntheses, properties, and applications of organic dyes and pigments. Angewandte Chemie International. 2003;43(40):5291-5292.
6. Siva R. Status of natural dyes and dye-yielding plants in India. Current science. 2007;92(7):916-925.

7. Jothi D. Extraction of natural dyes from African marigold flower (Tagetes erecta L) for textile coloration. Autex Research J. 2008;8(2):49-53.

8. Saravanan P, Chandramohan G. Dyeing of silk with ecofriendly natural dye obtained from Barks of Ficus Religiosa. L. Universal J Environmental Research \& Technology. 2011;1(3):268-273.

9. Ado A, Yahaya H, Kwalli AA, et al. Dyeing of textiles with eco-friendly natural dyes: a review. Int J Environ Monit Assess. 2014;1(5):76-81.

10. Sanjeeda I, Taiyaba AN. Natural dyes: their sources and ecofriendly use as textile materials. $J$ Environmental Research \& Development. 2014;8(3A):683-688.

11. Ado A, Musa H, Gumel SM, et al. Eco-friendly dyeing of cotton and polyester fabrics with natural dyes extracted from different varieties of kola nuts. International J Chemical \& Biomolecular Science. 2015;1(1):6-11.

12. Divya Lekshmi R, Ravi D. Extraction of Natural Dyes from Selected Plant Sources and Its Application in Fabrics. International J Textile \& Fashion Technology. 2013.

13. Ali S, Hussain Tanveer, Nawaz Rakhshanda. Optimization of alkaline extraction of natural dye from Henna leaves and its dyeing on cotton by exhaust method. J Cleaner Production. 2009;17(1):61-66.

14. Herrera CM. The fruiting ecology of Osyris quadripartita: individual variation and evolutionary potential. Ecology. 1988;69(1):233-249.

15. Herrera CM. The annual cycle of Osyris quadripartita, a hemiparasitic dioecious shrub of Mediterranean scrublands. $J$ Ecology. 1984;72(3):1065-1078.

16. Gulrajani M, Gupta D. Natural dyes and their application to textiles. Department of Textile Technology, Indian Institute of Technology, India; 1992.

17. Jothi D. Extraction of natural dyes from African marigold flower (Tagetes ereectal) for textile coloration. AUTEX Research J. 2008;8(2):49-53.

18. Kumaresan M, Palanisamy P, Kumar P. Application of ecofriendly natural dye on silk using combination of mordants. International J Chemistry Research. 2011;2(1):11-14.

19. Belemkar S, Ramachandran M. Recent Trends in Indian Textile Industry-Exploring Novel Natural Dye Products and Resources. International $J$ Textile Engineering \& Processes. 2015;1(3):33-41.

20. Kechi A, Chavan R, Moeckel R. Dye Yield, Color Strength and Dyeing Properties of Natural Dyes Extracted from Ethiopian Dye Plants. Textiles and Light Industrial Science and Technology. 2013;2(3):137.

21. Taif B, Som SHM, Yusof UZM. Extraction of Natural Dyes from Clitoria Ternatea Flower. MATTER: International J Science \& Technology. 2017;3(1):81-90.

22. Kechi A, Chavan R, Moeckel R. Ethiopian Dye plants As a Source of Natural Dyes for Cotton Dyeing. Universal J Environmental Research \& Technology. 2013;3(4):501-510. 